\title{
Effectiveness of an Oral Health Information, Education, and Communication Material on Knowledge, Attitudes, and Practices of Caregivers of Kindergarten Pupils in Manila, Philippines
}

\author{
Sittie Nor Rhizmin A. Tiang ${ }^{1}$, Michael Antonio F. Mendoza, DDM, MA ${ }^{2}$ \\ ${ }^{1}$ College of Dentistry, University of the Philippines Manila \\ ${ }^{2}$ Department of Community Dentistry, College of Dentistry, University of the Philippines Manila
}

\begin{abstract}
Objectives: It has been recognized that the knowledge, attitudes, and practices (KAP) of the caregivers affect the children's oral and general health. Prevention of oral diseases, like caries, can be achieved by providing oral health education (OHE) to caregivers, specifically mothers. Health educators have agreed that they are an important target group for OHE being "key figures" that provide the greatest influence on their child's life. This study intended to use and test the effectiveness of an Oral Health Information, Education, Communication (IEC) material which aimed to increase the caregivers' oral health KAP that would lead to dental visits of the children, regardless if symptomatic or not.

Methods: A one-group pretest-posttest design was used in the kindergarten classes of a public school in Manila, Philippines. The study utilized bilingual (Filipino-English) information sheets, pre- and post-test questionnaires after a 21-day period, and an Oral Health IEC material. Descriptive statistics were used to present and analyze the gathered data from the caregivers of kindergarten pupils.

Results: Though a low response rate of $9.93 \%$ was obtained $(\mathrm{N}=302)$ in the study, the respondents have displayed adequate level of knowledge, positive attitude, and good practice before the use of the IEC material. Significant improvement was noted with the post-test after the 21-day follow-up period. A change in practice was observed wherein $13.33 \%$ of the respondents sent their child/ward to the dentist regardless if symptomatic or not.

Conclusions: The Oral Health IEC material used was effective in increasing the KAP of the caregivers. Factors like dental pain, advice from friends/family, and the caregiver's personal decision have contributed to the child's dental visit after the 21-day period. The results of this study cannot be generalized to the entire population due to the low response rate.
\end{abstract}

Keywords: IEC material, primary teeth care, dental visit, kindergarten pupils, caregivers

Copyright (C) 2021. Korean Academy of Preventive Dentistry. All rights reserved.

This is an Open Access article distributed under the terms of the Creative Commons Attribution Non-Commercial License (http://creativecommons.org/licenses/ by-nc/4.0) which permits unrestricted non-commercial use, distribution, and reproduction in any medium, provided the original work is properly cited. 